\title{
ASPECTOS COMPOSITIVOS EN LAS SIETE CANCIONES POPULARES ESPAÑOLAS DE MANUEL DE FALLA [1914/15]
}

\author{
Cristina URCHUEGUÍA SCHÖLZEL, M. A. \\ Bayerische Julius Maximilians-Universität, Würzburg
}

La obra liederística de Manuel de Falla no abarca más de 18 piezas, de las cuales 17 fueron compuestas para piano y voz sola y una para voz y conjunto instrumental ${ }^{1}$. Comparada con el repertorio liederístico de Franz Schubert, Robert Schumann o Hugo Wolf o, si nos atenemos al ámbito del habla hispana, con Felipe Pedrell ${ }^{2}$ o incluso Isaac Albéniz, su producción resulta exigua. No obstante la inferioridad numérica respecto a los representantes del género par excellence y las fluctuaciones cualitativas, Manuel de Falla nos ha legado el ejemplo más notorio e importante de ciclo de canciones de la historia musical española del comienzo del siglo XX. Me refiero por supuesto a sus Siete Canciones populares Españolas ${ }^{3}$ que, sin querer minimizar la significación de su ciclo de canciones francesas Trois Mélodies y de sus canciones sueltas, justifican por sí solas el considerar a Falla como ejemplo paradigmático de "Liedkomponist". Muchas son las razones para centrarme en este ciclo. Por una parte el hecho de que se trate de canciones en castellano - el análisis de las obras en francés sólo se puede hacer desde el contexto de la evolución de la "mélodie" francesa- por otra la consecuencia que Falla desarrolló en el

1. Ediciones de las canciones para voz y piano: Manuel de Falla: Canciones de Juventud, Revisión Miguel Zanetti, prólogo Antonio Gallego, Madrid [Manuel de Falla Ediciones] 1993. Incluye: Preludios, Olas Gigantes, Rima, iDios mío, qué solos se quedan los muertos!, Tus ojillos negros. Canción andaluza. Idem: Obras desconocidas, vol. 1-3, ed. Enrique Franco, Madrid [UME] 1980. Incluye: Preludios, Olas Gigantes, Rima, ${ }_{i}$ Dios mío, qué solos se quedan los muertos!, Oración de las madres que tienen a sus hijos en brazos, Canción andaluza, El Pan de Ronda. Idem: Trois Mélodies, París [Salabert] 1910, (reedición 1989). Idem: Siete Canciones populares Españolas, París [Eschig] 1923. Incluye: 1. El paño moruno, 2. Seguidilla murciana, 3. Asturiana, 4. Jota, 5. Nana, 6. Canción y 7. Polo. Idem: Soneto a Córdoba, London [Chester] 1956. Para voz y con junto instrumental: Idem: Psyché, London [Chester] 1927.

2. Alfred ReIfF: Ein Katalog zu den Werken von Felipe Pedrell, en: AfMw III (1921), pp. 86-97.

3. A falta de una edición crítica de la obra de Falla me refiero aquí siempre al texto según la edición arriba indicada en la versión para voces agudas. 
proceso genético del ciclo y por último su naturaleza ambigua a caballo entre la esfera musical popular, con las concomitancias de hecho artístico natural que ello conlleva, y la música artificial.

Precisamente en su origen popular se ha centrado la discusión científica y los análisis de esta obra con una pertinacia, a mi entender, excesiva, aun cuando todos los estudiosos de la obra de Falla coincidan de un modo intuitivo en atribuirle al ciclo cualidades artísticas intrínsecas, no imanentes a las melodías que sirvieron de base a su composición ${ }^{4}$. Kurt Pahlen las denomina en su monografía "obras maestras", Jaime Pahissa habla incluso de "verdaderos lieder [sic] del más elevado abolengo" 5 . La gran resonancia del ciclo entre compositores e intérpretes así como el público tanto español como extranjero es indicador de un interés hacia algo que va más allá de ser una adaptación de música popular como pudieran serlo las armonizaciones de Federico García Lorca o las del mismo Manuel de Falla ${ }^{6}$. La cuestión que me planteo en este artículo es definir las particularidades compositivas que confieren al ciclo cualidades artísticas abstractas y establecer la posición del ciclo dentro de la tradición del género "Lied".

Si observamos el repertorio de canciones de Falla incluso superficialmente no podemos ignorar que muy pocas de las obras son realmente representativas de su estilo compositivo. Las obras de juventud no pasan de ser intentos de composición de marcado carácter epigonal, las canciones posteriores a 1915, esto es, posteriores a las Siete Canciones surgieron, "quasi" a desgana, a petición de poetas o como encargos. Únicamente Trois Mélodies y Siete Canciones dan fe de un interés real por el género surgido de "motu proprio" e inspirado en altas pretensiones artísticas. En el caso de Siete Canciones es precisa una matización. La motivación primera para la composición de Siete Canciones partió de una artista malagueña que trabajaba en la Opera Comique de París y que en 1914 encargó a Falla una serie de adaptaciones de melodías populares para interpretarlas el 10 de junio de 1914 en el teatro Odeón de París. Al saber Falla de la naturaleza de la "soirée" del Odeón - una especie de revista de variedades-, se negó a hacer entrega de las adaptaciones por considerar este marco inapropiado para sus obras. Se dispensó de su compromiso para con la cantante pero continuó trabajando en la composición de las

4. Suzanne Demarquez: Manuel de Falla, París [Flammarion] 1963, pp. 66-74, Roger Ernest Foltz: Pitch organization in Spanish music and selected late works of Manuel de Falla, Ph. D. diss. Univ. of Texas Austin 1977, pp. 109-114. Kurt Pahlen: Manuel de Falla und die Musik in Spanien, Olten und Freiburg i.B. 1954, (Musikreihe, Bd. 14), pp. 147-155. Thomas Garms: Der Flamenco und die spanische Folklore in Manuel de Fallas Werken, Wiesbaden 1990 (Neue musikgeschichtliche Forschungen, Bd. 16), pp. 143-186, entre otros muchos. De particular interés filológico son las contribuciones de Thomas Garms y García MATos: El folklore en La vida breve de Manuel de Falla, en: AnM XXVII (1971), pp. 173-197, idem: Folklore en Falla, en: Música (Madrid) III (1953), pp. 41-68 y VI (1953) pp. 33-52, idem: Sobre algunos ritmos de nuestro folklore musical, en: AnM XV (1960), pp. $101 \mathrm{ss,} \mathrm{und} \mathrm{XVI} \mathrm{(1961)} \mathrm{pp.} 27$ ss. en las que se alistan las documentaciones de música popular española contemporáneas a Manuel de Falla que pudieron haber servido de base a las melodías del ciclo.

5. Kurt Pahlen: Manuel de Falla und die Musik in Spanien, Olten und Freiburg i.B. 1954, (Musikreihe, Bd. 14), p. 147. "[Siete Canciones] werden erst durch seine kunstvolle Klavierbegleitung und Harmonisierung in den Rang von Meisterwerken erhoben." "[Siete Canciones] son elevadas al rango de obras maestras por su artístico acompañamiento y su armonización" Jaime PAhissa: Vida y obra de Manuel de Falla, Buenos Aires [Ricordi Americana]2 1956.

6. Me refiero a sus Cantares de Nochebuena, ed. y prólogo Antonio Gallego, Madrid [Manuel de Falla Ediciones] 1992. El interés hacia el ciclo Siete Canciones por parte de compositores se refleja en arreglos para otros instrumentos y en las orquestaciones de Luciano Berio y Rodolfo Halffter. Véase para una lista completa de las orquestaciones y arreglos: Antonio Gallego: Catálogo de obras de Manuel de Falla, Madrid [Ministerio de Cultura, Dirección Gral. de Bellas Artes y Archivos] 1987. Ronald CRIChton: Falla. Descriptive Catalogue of his Works, London 1976. Idem.: Falla-Berio, in: Financial Times, 17. März 1978, p. 21. 
adaptaciones hasta que el 20 julio de 1914 comunicaba a García Matos en una carta: "Son siete. He trabajado mucho en ellos. De algunos he hecho hasta tres o cuatro versiones hasta elegir la definitiva."7. Falla continuó trabajando en el ciclo hasta enero de 1915 mes en que, tras su vuelta a Madrid, fue estrenado. La fidelidad a sus ideales artísticos es en el caso de las Siete Canciones más digna de admiración dada la modestísima situación económica de Falla durante su estancia en París.

Esta breve descripción de la génesis del ciclo es necesaria para poder definir los parámetros externos que llevaron a su composición y la intención artística de Falla. El encargo de la cantante únicamente preescribía el origen popular de las melodías. Las fuentes melódicas del ciclo, el número de canciones y su ordenación en el conjunto obedecen al libre albedrío del compositor. Sobre los antecedentes que llevaron a la elección de las canciones no existen ni documentos epistolares ni ningún otro tipo de fuentes. Sin embargo, podemos reconstruir de modo ejemplar el camino seguido por al menos una de las melodías desde su descubrimiento por parte de Falla hasta la adaptación de $1914-15^{8}$. En la colección de armonizaciones de canciones navideñas Cantares de Nochebuena realizada por Falla en 1903-4 encontramos la melodía de la sexta pieza de Siete Canciones, Canción, en una versión algo diferente. En Cantares la melodía presenta un texto diferente de temática navideña con el incipit "Un pastor lleva un pavo" y está anotada en modo menor.
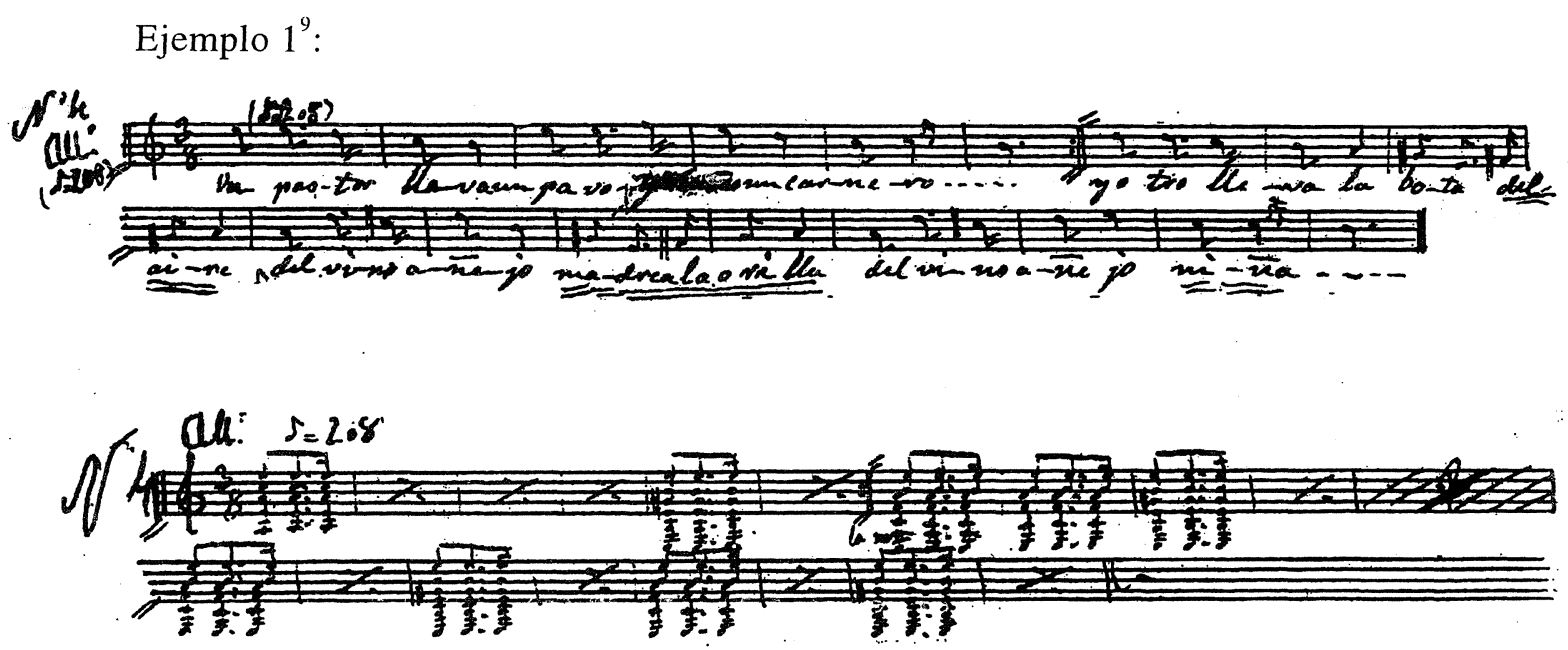

7. Carta citada en: GALLEGo/1987, p. 91.

8. Este extremo ha sido observado y descrito ya por Antonio Gallego en GaLLEGo/1992, pp. 3-4. Gallego data la colección de adaptaciones populares los años 1903/4 y manifiesta su opinión de que las melodías que utilizó Falla son documentos de primera mano. Es por estas razones falsa la afirmación de Foltz/1977, p. 109: "The seven Spanish Popular Songs for voice [...] was [Falla's] major attempt to seek out authentic music to serve as a basis of a composition. In many respects, however, these songs were written in much the same manner that Bizet had written his Spanish songs for Carmen; that is, Falla went to the library and found seven Spanish songs which he reworked and harmoninzed into a collection of songs." La relación de Falla con la música popular no era en ningún caso simplemente filológica.

9. Facsímil del autógrafo de "Un pastor lleva un pavo", publicado en: Manuel de FALlA: Cantares, p. 29-30. En este punto quiero expresar mi agradecimiento a D. Oliver Wiener por la realización y diseño de los ejemplos musicales. 
Falla encontró con anterioridad a las adaptaciones de 1914 una versión distinta a la de Cantares en la colección de melodías populares Ecos de España de Inzegna ${ }^{10}$ aparecida en Barcelona (s.d.) con dos estrofas distintas y en modo mayor. En el ejemplar de este libro en la biblioteca de Falla aparece en una nota marginal de su puño y letra la corrección del género tonal. La versión melódica y textual de Canción coincide en género tonal y texto con la segunda estrofa de la versión de Inzegna. No es posible decidir si la elección de la versión melódica de Inzegna obedeció a criterios de autenticidad o al gusto estético del compositor ${ }^{11}$. Sin embargo queda demostrada la actitud de Falla, interesada y crítica, por el documento popular. El encargo de la cantante cumplió la función anecdótica de motor de arranque para una actividad compositiva cuyas premisas musicales ya existían, latentes, en el subconsciente musical del compositor.

No podemos seguir el camino de todas las melodías desde su descubrimiento hasta su adaptación tan detalladamente como lo podemos realizar con Canción. Sabemos no obstante gracias a los trabajos fundamentales de Antonio Gallego y Thomas Garms las fuentes que pudieron haber estado al alcance de Falla ${ }^{12}$. Es por ello insatisfactorio, que la comparación de la melodía popular con la versión en las canciones de Falla se limite en el caso de Suzanne Demarquez, Kurt Pahlen o incluso Thomas Garms simplemente a la afirmación de que Falla ha adoptado las melodías "en su mayor parte" o "casi sin modificación" ". Se entiende por sí mismo que modificaciones substanciales en la adaptación de las melodías originales habrían puesto en peligro su identidad. Son las pequeñas modificaciones las que dan fe de la inspiración y el saber artístico del compositor, por lo que es necesario realizar un análisis detallado de esas divergencias. Garms concluye su análisis con la observación:

"No se trata en este caso de la abstracción de las características estilísticas básicas o esenciales de la canción popular con la meta de producir composiciones autónomas, sino de la exposición del material tradicional bajo signos estilísticos personales. [...] Las Siete Canciones populares Españolas transmiten el efecto de obras artísticas con un refinado acompañamiento, lo que no soslaya su origen popular y su originaria destinación extraartística." 14

Negarles a las Siete Canciones la autonomía artística justifica, de paso, el método seguido por Garms que se limita a la identificación de los elementos populares y de la fuentes melódicas: Una aproximación a la obra que parte de la base de que la presencia estética de un artefacto artístico es igual a la suma de sus elementos. La historia de la cultura nos ha enseñado que la

10. José INZEgna: Ecos de España, Barcelona s. d.

11. Sobre los motivos que llevaron a la elección de la estrofa hablaré más tarde.

12. Manuel García Matos: Folklore en Falla, en: Música (Madrid) III (1953), pp. 41-68 y VI (1953) pp. 33-52. Thomas GaRms: Der Flamenco und die spanische Folklore in Manuel de Fallas Werken, Wiesbaden 1990 (Neue musikgeschichtliche Forschungen, Bd. 16), p. 143. Antonio GAllego: Prólogo de Cantares de Nochebuena, p. 5, indican las siguientes posibles fuentes: José Inzegna: Colección de Cantos y Bailes populares de España: Asturias, Galicia, Murcia, Valencia, Madrid 1888. José INZEGNA: Ecos de España, s. d. José HuRTADo: 100 cantos populares asturianos. Escritos y armonizados para canto y piano por José Hurtado, Bilbao 1890. Dámaso Ledesma: Cancionero salmantino, Madrid 1907. Eduardo OcóN: Cantos españoles con notas explicativas y biográficas, Málaga 1874. Federico Olmeda: Cancionero Popular de Burgos, Sevilla 1903. Entre otros muchos.

13. GaRms/1990, p. 107, en el original: "weitgehend [oder] fast unverändert". [Traducciones de la autora]

14. Ibidem, p. 146. 
descontextualización de un elemento cualquiera produce una modificación esencial en su calidad ontológica. Nuestro interés se centra por tanto en el producto artístico en su conjunto, en la interrelación de los elementos que lo conforman: melodía, armonía, ritmo, declamación, métrica y forma; esto es, en los elementos básicos del lenguaje musical. No es mi intención realizar un análisis completo y exhaustivo del ciclo sino señalar detalles representativos en la escritura musical. Para ello he optado por analizar algunas de las canciones bajo aspectos concretos de su factura, dando por sobreentendido, que las conclusiones sacadas de un análisis puntual son susceptibles de extrapolación.

\section{Aspectos armónicos en las Siete Canciones: Asturiana}

Intentar describir los desarrollos armónicos en la música de Falla desde la base de la armonía tonal se halla abocado al fracaso. Dos elementos han de ser considerados seriamente: la naturaleza modal del material melódico y el carácter "irracional" —entiéndase aquí el término desde el punto de vista de la armonía clásica - de algunos acordes en el acompañamiento instrumental de la música popular que, sin lugar a dudas, inspiraron en parte las armonizaciones de Siete Canciones. Manuel de Falla era consciente de la importancia de la modalidad como elemento constituyente de la música popular y consideraba ésta como un camino para romper con la monotonía de la dualidad menor/may or del lenguaje armónico clásico. Esta opinión surgió, sin lugar a dudas, gracias a la influencia que Felipe Pedrell tuvo en la formación de los conceptos estéticos en el joven Falla. Felipe Pedrell escribe, e.g., en el prefacio de su Cancionero:

"El arte oficial pierde entonces [en la época clásica] su elevación y repudia, temeroso de derogarla, la vieja canción inspiratriz. Los clásicos alemanes, hachuela en mano, destruyen la maternal frondosidad que cobijó la Edad Media; y substituyen la belleza lujuriante de las modalidades gregorianas, por la indigente alternación del mayor y del menor; el coral es el único vestigio que queda de la desterrada canción, y las distinciones de razas e idiomas se anulan en una impersonalidad deseada e infecunda." 15

Esta interpretación de la función de la modalidad y de su consunción en el ámbito de la música clásica alemana es, quizá, la razón de que Falla en sus Escritos cite en tono laudatorio únicamente una obra de Ludwig van Beethoven: el tercer movimiento del cuarteto op. 132: Dankgesang eines Genesenden an die Gottheit, in der lydischen Tonart (Canción de gracias de un reconvalescente a la divinidad, en modo lídico) como huella última del antiguo arte en la obra de esos "grandes maestros".

15. Felipe Pedrell: Cancionero Musical Popular Español, vol. 1-4, Valls 1922, vol. 2, p. 8.

16. Manuel de Falla: Escritos sobre música y músicos. Debussy, Wagner, el cante jondo, introducción y notas de Federico Sopeña, Madrid [Espasa-Calpe] ${ }^{3} 1972$, p. 40. 
Manuel de Falla basa su acercamiento a la armonía popular en las características armónicas específicas de la guitarra como instrumento acompañante. En su artículo sobre Cante Jondo define el carácter de las armonías de la guitarra como sigue:

"El empleo de la guitarra representa dos valores musicales bien determinados: el rítmico [...] y el valor puramente tonal-armónico. [...] la importancia del segundo [...] apenas ha sido reconocida por los compositores, exceptuando a Domenico Scarlatti, hasta época relativamente reciente.

$\mathrm{Y}$ es que el toque jondo no tiene rival en Europa. Los efectos armónicos que inconscientemente producen nuestros guitarristas, representan una de las maravillas del arte natural [...] puesto que rasgueando las cuerdas sólo acordes pueden producirse. Acordes bárbaros, dirán muchos. Revelación maravillosa de posibilidades sonoras jamás sospechadas afirmamos nosotros." 17

Es fácil imaginarse lo que Falla denomina "acordes bárbaros". El guitarrista que acompaña pisa para producir un acorde 4 cuerdas, rasguea empero las 6 cuerdas del instrumento, con lo que junto a las notas constitutivas del acorde suenan dos cuerdas al aire, por regla general y sin cejilla, mi y si. El acorde fa mayor sonaría así siempre juntorcon el tritono y la sensible de la tonalidad. Los acordes son enturbiados con elementos que no pueden ser explicados desde el punto de vista de la superposición de terceras. Manuel de Falla encontró en el tratado de un francés desconocido, Louis Lucas $^{18}$, la fundamentación teórica para explicar estos acordes.

Ahora bien, si intentamos describir procesos armónicos de esta naturaleza nos abandona la terminología. Así como la teoría musical moderna desde Rameau, Riemann, De la Motte o Gardonhy nos ha dado los instrumentos terminológicos para describir desarrollos armónicos tonales, no existen teorías equivalentes para la armonía modal o para describir acordes no triádicos $^{19}$. Podemos fijar las desviaciones de la norma tonal, pero no reducirlas a su principio último. La cuestión que me planteo es dilucidar hasta que punto podemos explicar las armonías en Asturiana tonalmente y cuándo es necesario ampliar los conceptos.

17. Falla/Escritos, pp. 153-55.

18. Louis LuCAs: Une revolution dans la musique: essai d'application "la musique, d'une théorie philosophique. Ouvrage précédé d'une préface par $M$. Theodore de Banville, et suivi du Traité d'Euclide (traduite par P. Forcadel) et du Dialogue de Plutarque (traduction de Burette) sur la musique, París 1849. Falla poseía probablemente la segunda edición con el título: L'Acustique nouvelle.

19. Teorías armónicas como la Pitch-Class Theory de Allan Forte o la armonía basada en la superposición de cuartas de Hindemith son en nuestro caso igualmente inapropiadas. La tesis doctoral de Roger Ernest FolTz: Pitch organization in Spanish music and selected late works of Manuel de Falla, Ph. D. diss. Univ. of Texas Austin 1977 (inédita), representa un intento de encontrar explicación al carácter armónico de la música de Manuel de Falla, que a mi entender, concede significación absoluta al elemento popular, sin tener en cuenta la lógica interna de los desarrollos armónicos en la música de Falla. 
He elegido Asturiana por presentar esta canción una estructura formal y melódica de particular sencillez. Podemos describir la forma de la canción así:

\begin{tabular}{|c|c|c|c|c|c|}
\hline \multicolumn{3}{|c|}{ Estrofa } & Compás & Texto & Cadencias \\
\hline & Preludio & $1-7$ & & & \\
\hline \multirow[t]{4}{*}{$\mathrm{I}$. } & A & & $8-12$ & Por ver si me consolaba, & \\
\hline & $A^{\prime}$ & & $13-15$ & Arriméme a un pino verde & \\
\hline & B & & $16-18$ & Por ver si me consolaba & fa-do \\
\hline & Interludio & & \multicolumn{2}{|c|}{$19-20(=6-7)$} & \\
\hline II & A & & $21-24$ & ¡Por verme llorar, lloraba, & \\
\hline & $A^{\prime}$ & & $26-28$ & Y el pino como era verde, & \\
\hline & B & & $29-31$ & Por verme llorar, lloraba! & [re-la]-sol \\
\hline & Postludio & & $32-38$ & & [re-fa $\#-l a]-$ sol \\
\hline
\end{tabular}

El material melódico de Asturiana pertenece al ámbito de la modalidad dórica auténtica (aquí sobre sol) $^{20}$. Asturiana presenta en la melodía dos estrofas cuya estructura interna consta de dos mudanzas [A y A'] y una cauda [B], finalizando las mudanzas en el segundo tono de la modalidad, la cauda, cuyo carácter es conclusivo, desemboca en la finalis. El ámbito melódico no supera la sexta, el ámbito más reducido de toda la producción liederística de Falla. Podemos describir las mudanzas como ascensión en terceras de la finalis a la quinta del modo, el fa\# del principio no es más que una preparación, el la una nota de floreo de esta ascensión, sigue el posterior descenso hacia la penúltima la. La cauda resuelve la tensión en que finalizan las mudanzas, acabando en la finalis sol.

El preludio comienza con un pedal, realizado como alternancia entre do' y do" en figuración de semicorcheas en la mano derecha del piano. Acompaña la línea melódica preformulada por el piano en la mano izquierda. El efecto armónico de melodía y pedal es inestable y ambiguo. Las melodía parece encontrarse durante el preludio en mi b mayor, efecto que ya en el compás $4^{\circ}$ es contradicho por un la natural. En los compases 4-5 la melodía es conducida por grados conjuntos desde el Sol-bajo hasta el Re de la contra octava, escuchamos ahora el movimiento mi $b \rightarrow$ re no como movimiento sensible-tónica, sino como movimiento penúltima última de una cláusula frigia.

El Re del $5^{\circ}$ compás adopta el movimiento del pedal con la entrada de la voz. Las notas fa $\sharp \rightarrow$ sol de la melodía confieren al pedal sobre re carácter unívocamente dominántico con respecto a la melodía, que aparece esta vez en su forma original en el modo dórico. Las dos exposiciones de la melodía, aunque análogamente construidas, adoptan posiciones distintas dentro del espacio tonal.

20. La versión original de las canciones se encuentra una segunda mayor por debajo de la versión que he utilizado, por razones que no vienen al caso, para mis análisis. En el capítulo final de mi artículo he utilizado no obstante, las tesituras originales. 
Esta primera relación dominántica es inmediatamente debilitada en el compás $10^{\circ}$ mediante la superposición al pedal de la tercera mib/sol que aparece precisamente cuando la melodía alcanza su culminación en el re". En la segunda mudanza la desestabilización del efecto dominántico es reforzada con la subposición de la quinta mib/sib en la tesitura más baja hasta entonces alcanzada por el acompañamiento. El acorde formado por el pedal y la quinta suena hasta el penúltimo compás de la cauda en que asciende en un movimiento paralelo una segunda mayor. El paso de la a sol, penúltima-última, en la cláusula final de la primera estrofa, es armonizada con los acordes fa mayor do menor. La cadencia plagal no sustenta el carácter conclusivo del paso melódico la $\rightarrow$ sol en la melodía. Las quintas paralelas en la cláusula confieren a ésta un carácter arcaico.

La segunda estrofa presenta sutiles pero efectivas modificaciones. El clímax en la voz es armonizado con un retardo de cuarta, lo que agudiza la inestabilidad de la ya de por sí lábil estructura armónica. La cláusula final de la segunda estrofa resuelve en el acorde de la finalis del modo, sol menor, pero carece de sensible. Manuel de Falla ha evitado o rodeado hasta ahora toda relación acórdica claramente definida. Los acordes son integrados en el contexto de forma ambigua, contradiciendo en ocasiones su propia estructura. Ejemplo a señalar es el acorde $\mathrm{mi} / \mathrm{sol} / \mathrm{si}$ /re de los compases $12-17$ y $25-27$, cuya forma es la de un acorde de séptima de dominante de la $b$ mayor, pero cuya función no es en ningún momento apoyada por el contexto.

El camino hacia la cadencia final en el postludio pasa por la subdominante. Hecho éste, que no merecería mención, de no ser que el texto musical es idéntico al preludio, lo que explica a posteriori, el pasaje del preludio como desviación hacia la región subdominántica. Los últimos compases del postludio presentan una cadencia regular hacia sol menor, pasando por re mayor. El efecto de la cadencia es subrayado por la aparición por primera vez de fa \# como sensible de sol menor y por su prolongación más allá de la resolución del acorde de dominante.

Falla utiliza los medios armónicos de forma económica y sutil. Se sirve de la ambigüedad funcional de los acordes, prescindiendo de acordes con funcionalidad clara. A la configuración sencillísima de la melodía superpone Falla una construcción armónica jerárquicamente organizada. Las cesuras de la melodía son integradas en un sistema de cadencias funcionalmente escalonadas que van de menor a mayor tensión y efecto conclusivo: La canción comienza exponiendo, inadvertidamente, la subdominante, la primera estrofa finaliza con una cláusula plagal, que evita el acorde de la finalis, la segunda con una cadencia auténtica hacia la finalis, evitando la sensible, el postludio expone por primera vez y de modo decidido la sensible. Poco a poco se va cristalizando la dominante, que al fin aparece como verdadero acontecimiento. Esta, por llamarla de algún modo, armonización procesual, es solamente comprensible desde el contexto de la armonía tonal, puesto que vive de contradecir sus reglas. El desarrollo armónico de la canción obedece pues a una idea abstracta, que es desconocida por completo a la música popular, y que da fe de una sensibilidad armónica extraordinaria, dada la sencillez de la melodía popular y de la realización del acompañamiento.

[8] 


\section{Reflexiones sobre la función métrica y rítmica del acompañamiento: Nana}

La quinta canción del ciclo Nana se encuentra en una posición especial. Al tratarse de una canción de cuna, tenemos que partir de la base, de que el modelo popular estaba concebido para ser interpretado sin acompañamiento instrumental. Si observamos el modelo rítmico del acompañamiento veremos, que es imposible identificar ningún modelo rítmico popular como por ejemplo en Jota, Polo o Seguidilla murciana. Aún más, la melodía, que llegó a manos de Falla - con seguridad a través de Felipe Pedrell- parece carecer de superficie rítmico-métrica definida. Si comparamos tres versiones diferentes de la melodía en tres documentaciones de la época y posteriores veremos que la versión de Eduardo Ocón, conocida tanto a Pedrell como a Falla, no tiene indicación de compás, la versión de Felipe Pedrell está anotada en compás de 3/4, la versión de Manuel de Falla en Siete Canciones en 2/4. Finalmente, y a título anecdótico, citemos la versión muy posterior de José Hidalgo Montoya en su Cancionero de Andalucía, que mezcla las versiones de Ocón y Felipe Pedrell, adoptando la tonalidad de Ocón y el compás de Pedrell $^{21}$.

Ejemplo 2 (Ocón):

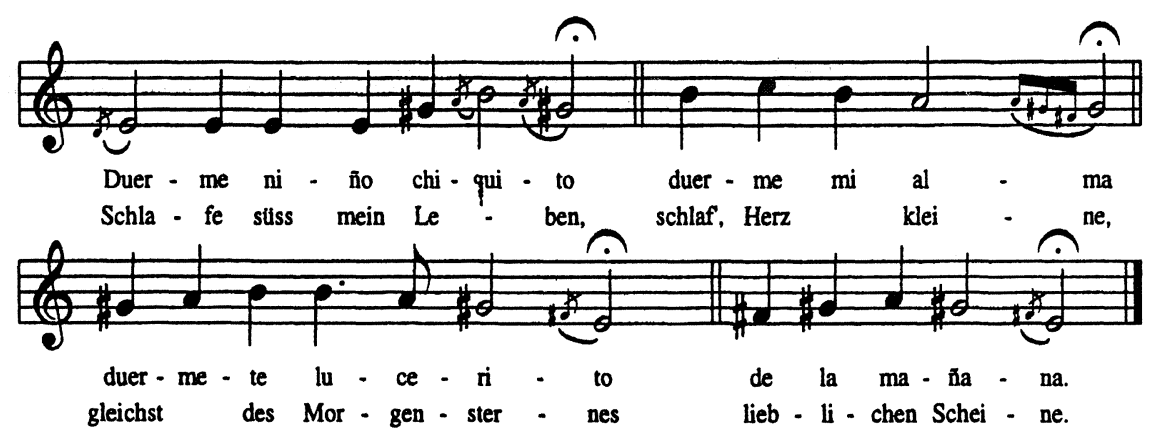

21. Eduardo Ocón/1874, p. 100; Pedrell/Cancionero, tomo 1, p. 2; Juan Hidalgo MontoyA Cancionero de Andalucía, Madrid [Antonio Carmona] 21984, p. 11. 
Pedrell:
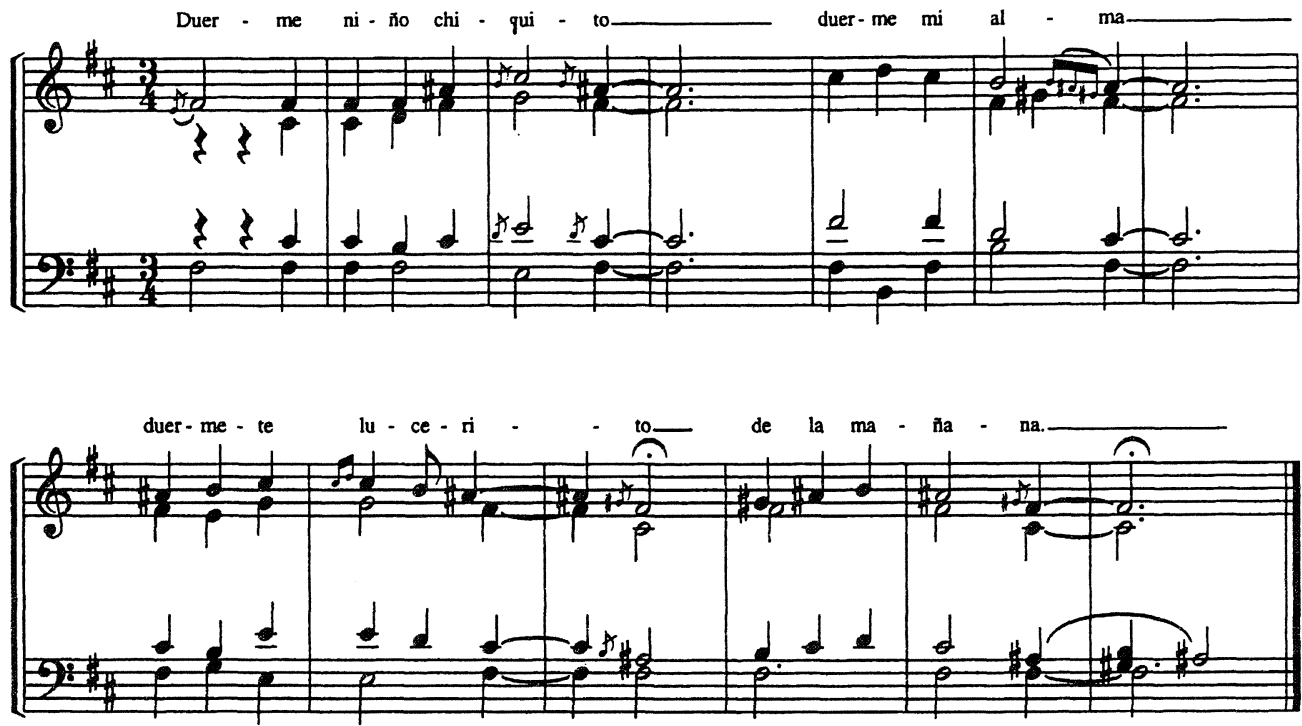

Hidalgo Montoya:

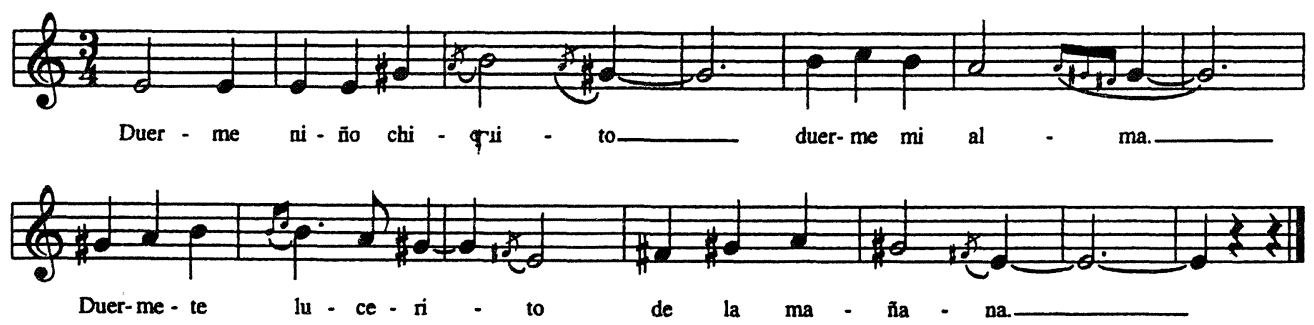

La conclusión que podemos sacar de estas anotaciones divergentes es que estamos aquí ante una melodía métricamente indiferente, o dicho de otro modo, de una música cuya estructura métrica obedece sólo y únicamente al impulso espontáneo del intérprete y a la estructura misma del texto. En última instancia podemos suponer, que todas las versiones parten de la primera versión de Eduardo Ocón, transformándola según la individual intuición musical del documentador. La afirmación de Jaime Pahissa en su biografía de Falla, de que éste conocía esta melodía desde su infancia, es ciertamente evocativa, y podría explicar las divergencias en el texto musical de la adaptación ${ }^{22}$.

La forma del texto está basada en el tipo "copla de seguidilla". El texto en la versión de Falla presenta con respecto a los otros una ampliación.

22. Pahissa/1956, p. 83 . 
Nr. 5 NANA

I Duérmete niño, duerme

Duerme mi alma

Duérmete lucerito

De la mañana

II Nanita, nana

Duérmete lucerito

De la mañana.
NANA (Ocón) $)^{23}$

Duerme niño chiquito

Duerme, mi alma

Duérmete lucerito

De la mañana

La repetición del primer verso de la segunda estrofa —el casi onomatopéyico "Nanita, nana"- y la repetición del último verso de la primera estrofa parten el texto de la canción en la versión que nos interesa en dos: la primera parte es la copla de seguidilla, la segunda un terceto con el esquema métrico $5+7+5$. El esquema resultante corresponde a la copla de seguidilla compuesta, que encontramos también en Seguidilla murciana.

Cada verso del texto está musicalizado en una frase musical independiente cuya forma describe un arco: asciende hasta un clímax melódico y acaba en un melisma descendente anotado con extraordinaria precisión. En una conversación con Juan María Thomas encontramos la razón de está particular forma de escritura:

\begin{abstract}
"Acaba de estar aquí una de las cantantes francesas más famosas, que estando de paso quería aprovechar la ocasión y pedirme consejos sobre su interpretación de mis "Siete Canciones". Hablaba de "su interpretación", y ciertamente tenía un noción tan personal de estas canciones, que casi no puedo hacer valer con buena conciencia mis derechos de autor, si ella las canta $[\ldots]$

He intentado explicarle lo que cuesta, anotar las gradaciones y las inflexiones de modo que correspondan al carácter popular que cada canción exige. Espero que me haya entendido, aunque he hecho muy malas experiencias con este tipo de conversaciones. A menudo sólo sirven para que el intérprete, sin tener en cuenta mis consejos - siguen haciendo los mismos errores que antes - pueda aludir en el programa a nuestra conversación. Ello les permite presentar sus acrobáticas cabriolas como "versión auténtica siguiendo las advertencias del autor". Los temo, los temo mucho, sobre todo a los americanos." 24
\end{abstract}

No es por tanto una casualidad que Falla escribiera los melismas exactamente y no, como en las versiones de Ocón y Pedrell, en forma de ornamentos. La otra modificación en la melodía es la ampliación en la versión de Falla del ámbito de la sexta original a la octava.

El comienzo de la melodía obedece en la versión de Falla a un impulso rítmico implicado ya en el texto. Vemos que las versiones textuales de Ocón y de Falla difieren en el primer verso: Ocón comienza con el imperativo "duerme”, Falla le añade el pronombre reflexivo "duérmete" y convierte así la palabra en un proparoxytonon, en palabra esdrújula.

23. Ocón/1874, p. 100.

24. Manuel de Falla: Spanien und die neue Musik. Ein Lebensbild in Schriften, Bildern, Erinnerungen, übersetzt und hg. v. Jacoba Grunfeld, Zürich 1968, p. 110. Desgraciadamente he encontrado esta cita sólo en la versión alemana de los escritos de Falla. 
El ritmo característico de la palabra esdrújula es realizado musicalmente con un tresillo, que aparece por tanto como reflexión del ritmo hablado, una observación que podemos ampliar a la totalidad de la melodía.

A esta melodía "textual", métricamente libre superpone Falla un acompañamiento cuya regularidad produce, ya de por sí un efecto contrastante. Consiste éste en un modelo rítmico de corcheas que desciende formando segundas y terceras y repitiéndose con pequeñas variantes durante toda la canción. La mano izquierda repite este modelo a contratiempo de una semicorchea. Podemos encontrar un movimiento comparable en The snow is dancing de Children's corner de Claude Debussy o en la chanson Spleen de Gabriel Faurée ${ }^{25}$.

Ejemplo 3 (Debussy):
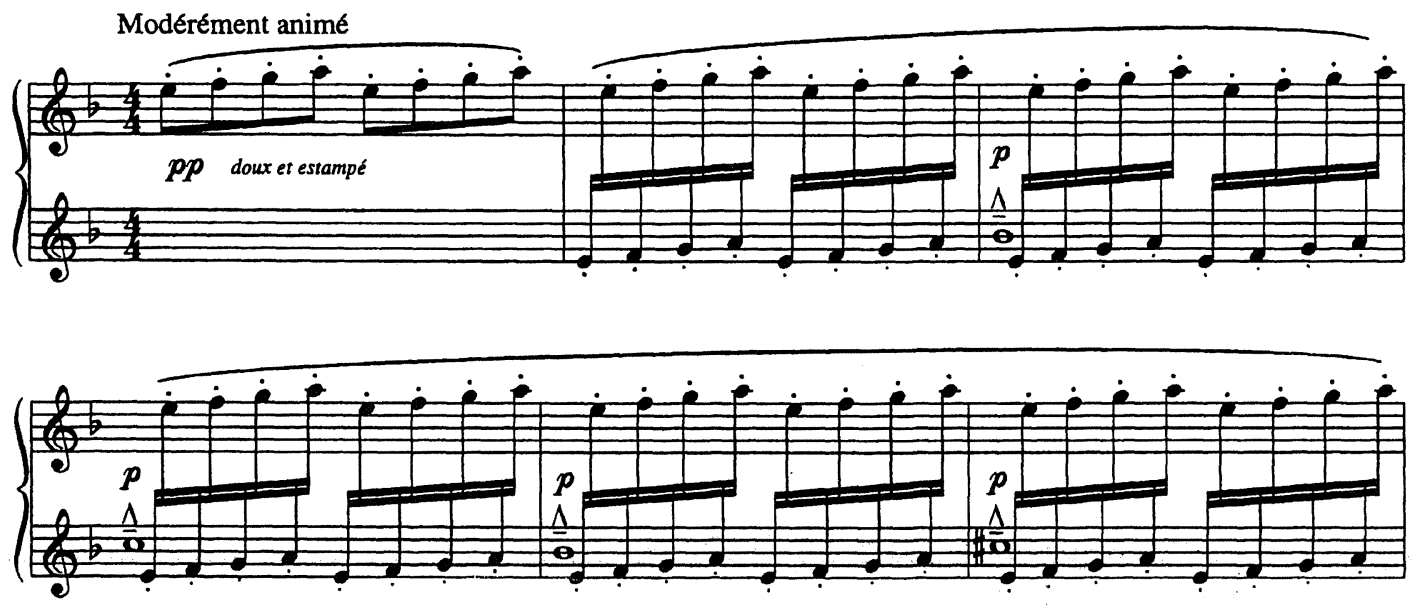

Fauré:

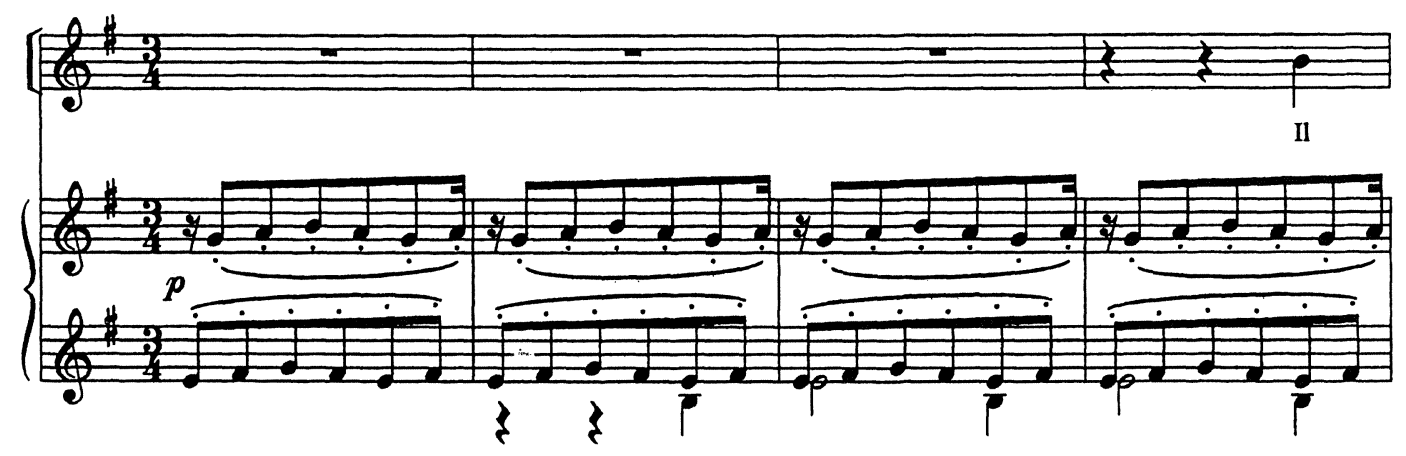
compases 1-8

25. Claude DeBussy: Children's corner, IV. The snow is dancing, compases 1-6. Gabriel Fauré: Spleen, op. 51/3, 


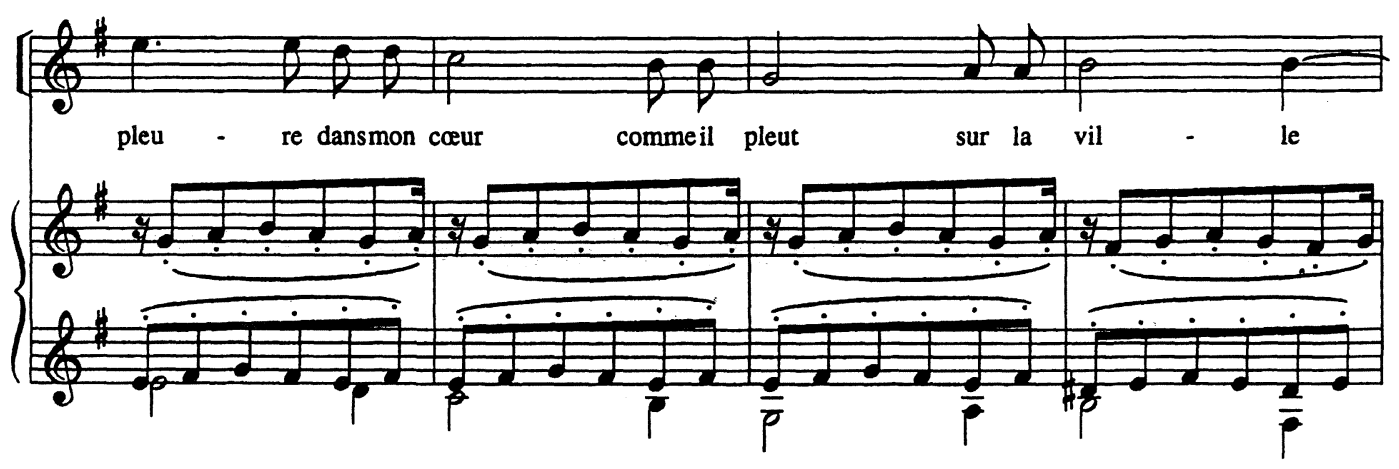

Pero si observamos estas piezas detenidamente veremos que Falla juega, a diferencia de las obras de Fauré y Debussy, ambiguamente con los acentos del compás a pesar de la regularidad rítmica producida por la repetición compás por compás del modelo del acompañamiento. El hecho de que la nota acentuada del compás recaiga siempre en el registro agudo y la nota a contratiempo en el registro grave deslava la estructura métrica del compás. Si intentamos ejecutar la canción tenemos que sobreponernos a la fuerza gravitatoria del bajo a contratiempo, tenemos que crear nuestros propios acentos métricos. Falla ha superpuesto a este acompañamiento métricamente ambiguo en su total simplicidad los acentos métricos del texto. El acompañamiento nos ofrece un tapiz rítmicamente regular, cuya contradictoria estructura métrica ni acompaña ni concurre contra la métrica textual.

Un pedal sobre fa $\sharp$ apoya el horizonte métricamente regular del acompañamiento. Falla construye sobre este pedal armonías que pertenecen siempre al contexto armónico de fał. En la primera parte alternan fa $\sharp$ mayor y fa $\sharp$ menor. El fa \#adopta la función de bajo de una dominante hacia si menor o de tónica de fa\# menor. La discreta aparición de un re' en los compases 4-7, 9-10 y 11-12 subrayan la importancia de la subdominante si menor. La primera parte de la canción empieza y finaliza sobre fa $\sharp$ mayor en función dominántica con respecto a si menor; la segunda parte finaliza en la tónica fa \# que aparece aquí transformada por medio de una tercera de Picardi en mayor. Salta a la vista la total ausencia de la dominante de fa $\#$. El mi \# no aparece tan siquiera como nota de adorno en los melismas. Así podemos describir el desarrollo armónico de Nana como alternancia entre la subdominante y la tónica, en que se han invertido las funciones, la tónica aparece como función de la subdominante, como su dominante.

El acompañamiento de la primera parte de la canción se limita a la alternancia entre fa\# mayor y fa \# menor. La segunda parte es una variante con carácter climático de la primera. Las diferencias substanciales se deben en parte a diferencias en el texto, en parte al carácter climático de la segunda parte. El comienzo del tercer verso en la segunda parte es idéntico al comienzo del tercer verso en la primera. La melodía desciende en la primera parte del mi" al do \#"; el la segunda culmina en un fa\#", que apareciendo aquí por única vez sobre el acento del compás marca el 
clímax de la canción. El acompañamiento subraya este momento ampliando su ámbito una tercera por encima del ámbito hasta entonces alcanzado y añadiendo al acorde de fa \# la séptima y la novena.

La primera estrofa presenta una superficie relativamente homogénea y vaga contra la que puede elevarse el clímax de la segunda parte. El devenir armónico carece no obstante de perfil propio, es en todo momento vago y débil. Su punto culminante no obedece al principio de tensión tonal y no desemboca en una cadencia sino que se disgrega hasta su desaparición. El acompañamiento es un perpetuum mobile estructurado pero quebradizo, capaz de responder a la tensión de la voz pero incapaz de producir desarrollos armónicos estringentes. Refleja la tensión cuantitativa pero no cualitativamente.

Falla no reproduce aquí simplemente la melodía popular, dibuja una escena, un ambiente. Como en Margarita en la rueca, de Schubert sobre texto de Goethe sentimos la dimensión semántica del acompañamiento, su fuerza estructurante pero carente de perfil propio. No podemos limitar la función del piano, del movimiento regular a su mera componente mimética, que podríamos interpretar tanto aquí como en la canción de Schubert como el mecer de una cuna. El impulso evocador semántico se consuma empero en la epidermis de la canción, y contiene en su poder inmediato de alcanzar nuestro oído, un valor primigenio al que no podemos sustraernos. Sutilmente, sin desvirtuar el carácter popular del modelo melódico, crea Falla un universo artístico propio, estructurado y significativo. Podemos por tanto definir esta canción como "Lied" en el sentido más literal de la palabra.

\section{Consecuencias del modelo popular para la declamación: El Paño moruno}

A primera vista parecerá fuera de lugar tematizar la relación música-palabra, la declamación en el caso de melodías populares. El modelo preescribe una relación unívoca entre texto y melodía, cuya modificación implicaría, en la mayoría de los casos, consecuencias graves para el modelo mismo. El compositor no tiene más recursos que adoptar las "faltas" del modelo, y hacer de ellas lo mejor. Estas faltas suelên manifestarse en discrepancias entre acentos textuales y acentos melódicos, que, simplificando, suelen aparecer a partir de la segunda estrofa de estas canciones. Si partimos del hecho que la obra de Falla está en gran parte basada en textos, tenemos que suponer que el compositor era perfectamente consciente del fenómeno. Y, si analizamos su obra con atención, veremos que no se dejó amilanar por él, sino que intentó, como p. ej. en la canción que analizaré a continuación, crear compromisos plausibles entre el documento y su interpretación artística.

La primera canción del ciclo El paño moruno presenta en la versión de Manuel de Falla, tanto en el texto como en la música, pequeñas diferencias con respecto al modelo popular, que podríamos interpretar como intentos de corregir la declamación errónea y de suavizar yuxtaposiciones armónicas, que desde el punto de vista tonal, resultan algo abruptas. 
La forma de la canción corresponde exactamente al modelo:

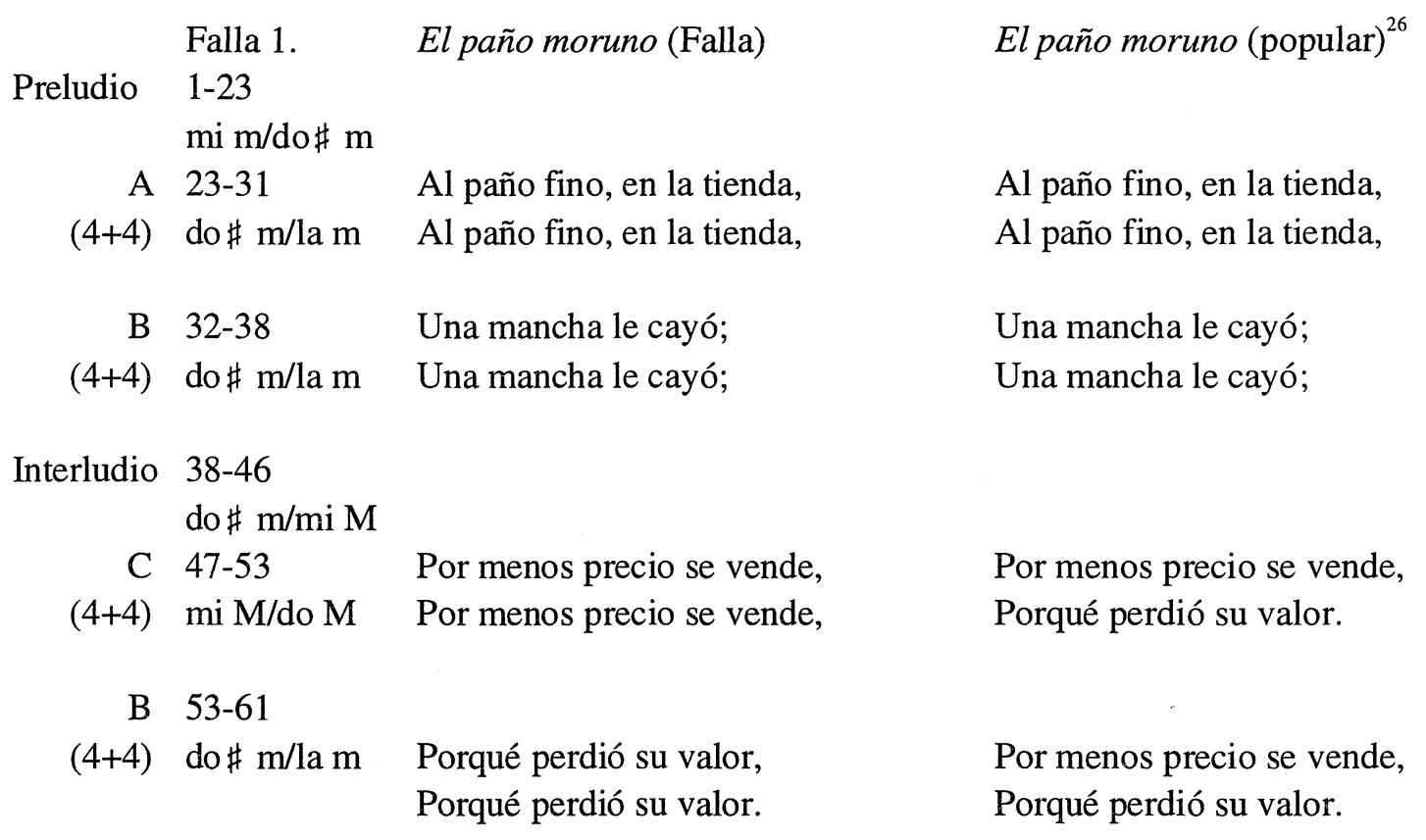
Postludio 61-76 ¡Ay!
re $\#<^{7+} /$ do $\# \mathrm{M}$
cadencia frigia

Falla ha cambiado el orden de aparición de los últimos versos dejando la idea principal del texto concentrada en último lugar pero sin modificar la melodía. No puedo afirmar que este cambio sea original de Falla puesto que las versiones populares que conozco no pueden haber servido de modelo. Thomas Garms afirma que las versiones textuales de documentaciones de la época son iguales a las de Falla pero ateniéndose únicamente el núcleo del texto y no las repeticiones $^{27}$. Si comparamos la melodía popular con la de Falla observamos, en la versión de Falla, dos cambios aparentemente inmotivados del compás del 3/8, en que está escrita la canción al de $3 / 4$. . Esta apariencia se debe a que los cambios de compás no aparecen en lugares análogos y no parecen tener ninguna influencia en la configuración rítmica y melódica.

26. HIDALGO/1984, p. 63.

27. GARMS/1990, p. 150. 
Ejemplo 4:

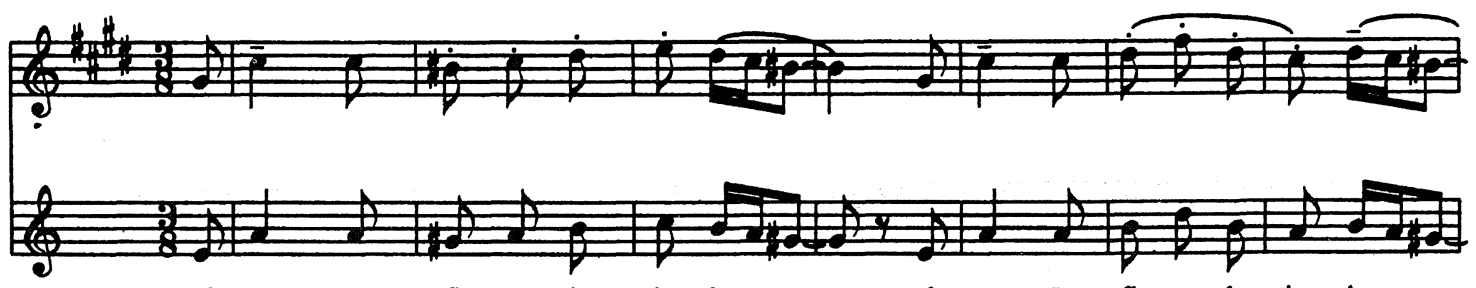

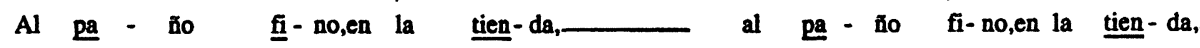
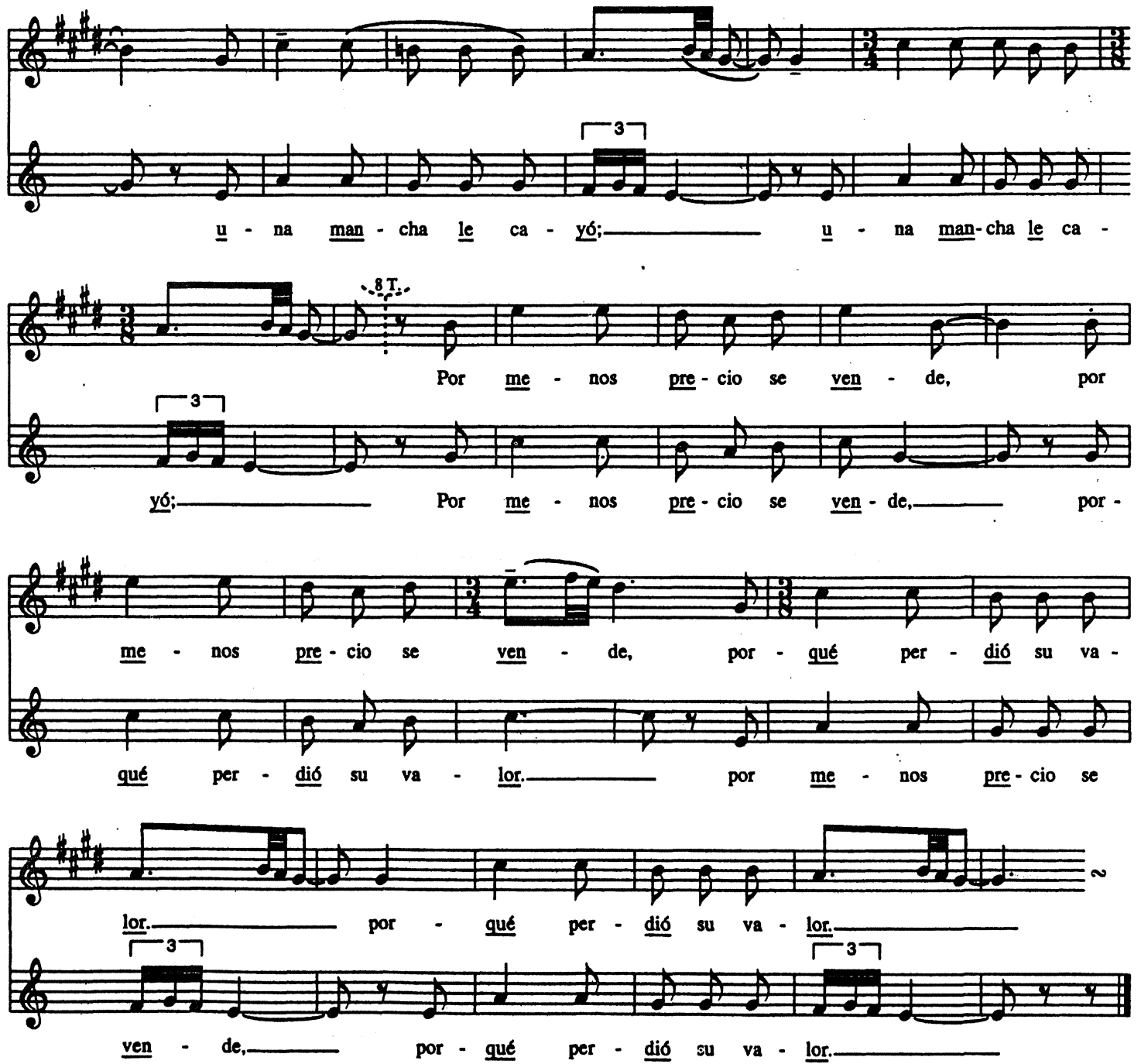
El primer cambio de compás aparece en el compás 12 de la melodía con el texto "[u]na mancha le ca[yó]”. La melodía sólo se diferencia del modelo en una sola nota. La razón del cambio de compás estriba en una discrepancia entre la acentuación del texto y la acentuación de la melodía:

Acentuación del texto: Una mancha le cayó

Acentuación melódica: Una manchạ le cayó

Esta discrepancia es reforzada por el ritmo básico de la canción que con su carácter permanentemente anacrúsico, subraya la primera nota del compás. La primera aparición del tercer verso mantiene el ritmo del modelo, en la repetición es cuando Falla introduce el cambio de compás al 3/4, que desplaza la acentuación de forma que coinciden la acentuación del texto con la de la melodía. La única sílaba que no participa del desplazamiento de los acentos melódicos es "Una". Falla suaviza la anacrusa alargando la nota sobre la que se canta la "U" de una corchea, como correspondería al ritmo básico de la melodía, hacia una negra. Este pequeño "truco" tiene por tanto una clara intención, corregir una declamación defectuosa, esto sí, dentro de un contexto musical lógico. Una vez hemos escuchado la versión original del tercer verso, es cuando Falla hace la corrección. El compás de 3/4 es uno de los medios que utiliza Falla para "componer" el final de la estrofa. Éste no sólo corrige la declamación, sino que crea un efecto de ralentización del ritmo básico, el "ritardando" sobre el cambio de compás tiene aquí casi una función pleonástica.

La segunda aparición del cambio de compás no se debe a la declamación. En la versión popular sucede entre el sexto y el séptimo verso una desviación que, interpretada armónicamente, correspondería al salto sin solución de continuidad de la tonalidad paralela mayor a la paralela menor. La melodía del sexto verso de la versión popular finaliza con el paso $s i \rightarrow$ do (sensible-tónica en do mayor), el séptimo verso comienza con un salto de cuarta mi $\rightarrow$ la (dominante tónica de la menor). Falla evita esta relación mediántica, paratáctica y un tanto inorgánica mediante la inclusión de un desarrollo modulatorio que suaviza el paso de la tonalidad paralela mayor a la tonalidad paralela menor. El verso "por menos precio se vende" y su repetición se encuentran en mi mayor, tonalidad mayor paralela de la tonalidad principal do \# menor, quitando la última sílaba de la palabra "Vende" en el compás 53. Es aquí donde Falla introduce el cambio de compás, cuyo segundo tiempo expone, sobre la última sílaba del verso, la dominante de la tonalidad paralela menor, do \# menor. La melodía corresponde al giro armónico con un paso descendente hacia re \#", apoyado por un corto melisma. La melodía es, a excepción del corto melisma, idéntica a la melodía popular.

La última corchea del compás de 3/4 tiene la función de anacrusa dominántica para con el último verso del texto que se encuentra en la tonalidad principal do $\#$ menor, y que en la versión de Falla comienza, gracias a que el acompañamiento modula antes de empezar el verso, sobre la misma armonía con que finalizara el complejo musical anterior. De este modo ha construido Falla una relación hipotáctica, una transición suave. La función del cambio de compás no es otra que 
interrumpir el devenir métrico con un gesto hemiólico sin influir en el ritmo de la melodía. El acorde de dominante habría recaído, sin el cambio de compás, en el segundo tiempo del compás adquiriendo valor anacrúsico. De lo que se trataba en cambio era de modificar la métrica para introducir la meta de la modulación sobre un tiempo acentuado del compás.

Falla no adopta a la búsqueda de un compromiso entre las leyes de la lógica musical y el respeto hacia las características propias del documento popular una postura radicalmente consecuente. En ocasiones prevalece el detalle folclórico, en ocasiones la lógica intrínsecamente musical. En primer plano está siempre la intuición del compositor y su sensibilidad para con la forma orgánica. El hecho de saber cuál podría haber sido la motivación de Falla, no le quita sin embargo a la canción un ápice de su efectividad.

\section{A propósito de la estilización de modelos rítmicos populares: Polo}

El acompañamiento de la última canción del ciclo Polo está basado en el modelo rítmico típico procedente de la música popular andaluza. El ritmo básico de la canción y del baile popular vive de cambios periódicos de compás que aunque no estén explícitamente anotados podríamos describir del siguiente modo:

$$
(2 \times 6 / 8)+(1 \times 3 / 4)
$$

Falla se decide para la escritura por el máximo común divisor de ambos compases, el 3/8. El preludio de la canción expone este modelo rítmico dos veces, interpolando entre los modelos dos compases de 3/8 como margen de limitación. Con la entrada de la voz se convierte el modelo rítmico en tapiz métrico ininterrumpido. La exposición del ritmo es, en el caso de Polo, el motivo principal del preludio realizado por tresillos rápidos y punzantes que nos dan el canon de acentuación y repeticiones de tonos que llenan el compás.

El preludio consta de 32 compases que podemos estructurar en dos grupos de 16 compases. La melodía de Polo se encuentra en la modalidad frigia sobre $\mathrm{fa}<$, el primer grupo del preludio expone la dominante do<, el segundo grupo la penúltima sol. Ambos grupos aparecen como bloques armónicos yuxtapuestos. Con la entrada de la voz se modifica la estructura rítmica del acompañamiento a favor de un movimiento continuado de tresillos y el carácter lapidario del acompañamiento armónico a favor de desarrollos armónicos progresivos. Bien es cierto que, intercaladas en el ritmo básica del acompañamiento, podemos percibir sutiles hemiolas, pero éstas no restan protagonismo a la voz.

Podemos comparar la envergadura del preludio de Polo con el preludio de Jota. El efecto y la intención de Falla en estas canciones es bien distinto. El preludio de Jota substituye y evoca la alternancia de partes instrumentales y partes vocales del modelo popular y caracteriza las distintas partes con tonalidades y compases diferentes. Tiene por tanto una función formal. En 
Polo, en cambio, tiene la función de exponer un ritmo característico, que es elevado de este modo a la categoría de núcleo generador.

La realización pianística de este ritmo en la canción de Falla recuerda a obras de Isaac Albéniz. Pensemos p. ej. en su popularísimo Asturias ${ }^{28}$.

Ejemplo 5:
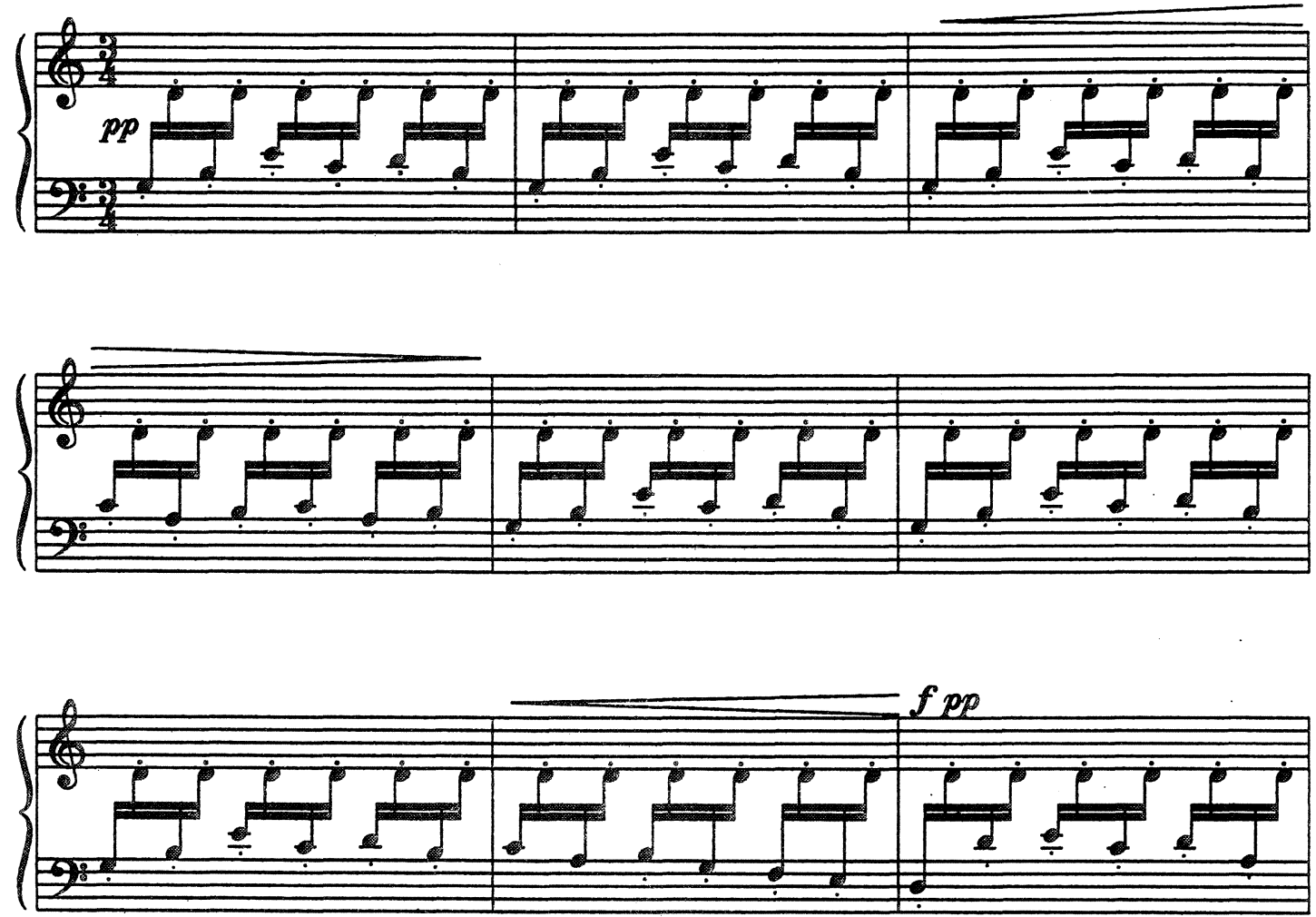

El modo de realizar desviaciones en la acentuación del compás es muy parecido. Isaac Albéniz entrelaza en una serie de repeticiones de notas una melodía que va marcando los acentos. Las repeticiones de tonos son una cadena indiferenciada en la que los tonos de la melodía introducen libremente acentos. También en Albaicín, la primera parte del cuarto volumen de su

28. Se trata de la quinta pieza de Suite espagnole. La suite fue compuesta entre 1886 y 1889 , y lleva el nr. de Opus 47. Asturias fue incluida en la suite de forma póstuma y lleva el nr. de Op. 231/1. Aun así es muy posible que Falla conociera esta obra dada su estrecha relación Isaac Albéniz ya durante la estancia en París. Véase: Tomás Marco: Art. Albéniz, Isaac, in: NGroveD, vol. 1, pp. 202-204. Henri Collet: Albéniz et Granados, París ${ }^{2}$ [Edition le bon plaisir] 1948. Mariano PÉrez Gutiérrez: El París que vivió Manuel de Falla y sus concomitancias estéticas, en: Revista de ideas estéticas XXXV (1977), pp. 115-135. Idem: Falla y Turina en el París de sus sueños: La amistad de Falla y Turina documentcda a través de sus escritos, en: AnM XXXVII (1982), pp. 129-147 y Amalia Roales Nieto: Manuel de Falla et París, en: Revue international de musique française XXVI (1988), pp. 85-92 para mayor información sobre esta relación. 
Suite Iberia opera con una técnica similar $^{29}$. La relación entre la cadena de repeticiones y la melodía entretejida es algo distinta. Aquí son los huecos en la repetición, los que indican una acentuación divergente.

Ejemplo 6:
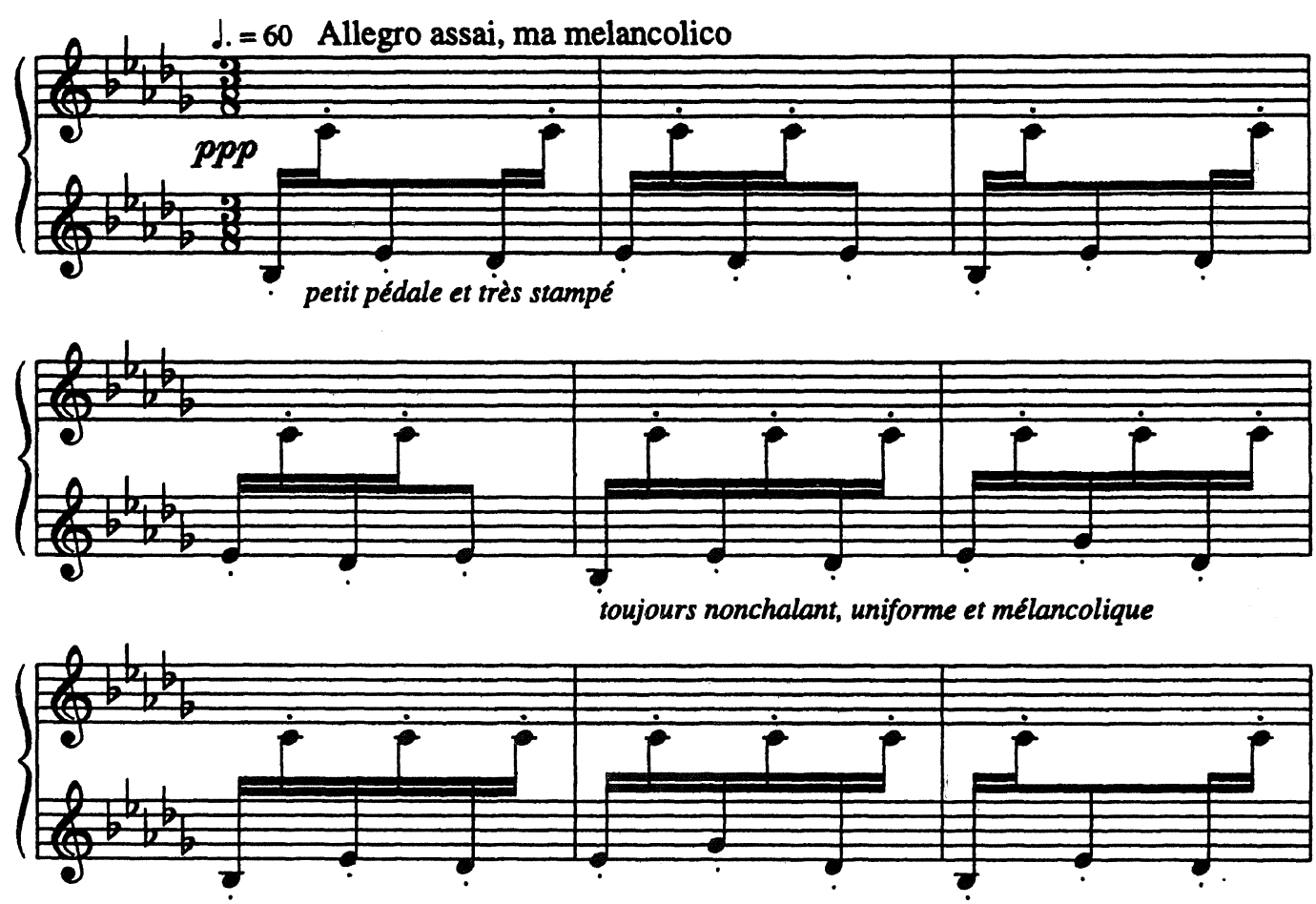

Falla ha reducido esta técnica a su principio último: una cadena de repeticiones interrumpida por acentos sin carácter melódico.

Falla adopta una característica de la música popular transcendiéndola hacia una forma abstracta pero sin quitarle su específica elementaridad. La idea que subyace es la de reducir un elemento musical a su germen, a su esencia. Falla se concentra en Polo en el elemento rítmico y métrico de la música popular, melodía y armonía juegan aquí un papel secundario. La influencia de este principio en la obra de Falla y el carácter abstracto de la idea quedan patentes en el hecho de que Falla utilizara una técnica muy similar y con función rítmica idéntica en música instrumental, p. ej. en el Concerto para clavecín de $1924-27^{30}$.

29. La obra carece de $n .^{\circ}$ de Opus, el año de composición es 1908 . Pérez/1977, p. 119 afirma que Falla hizo conocimiento de Albéniz durante la composición del cuarto volumen de la Suite Iberia con lo que podemos suponer que Falla conocía la obra aún antes de su aparición impresa.

30. He reducido el ejemplo a la parte de cembalo hasta la cifra de ensayo 5 .

[20] 
Ejemplo 7:
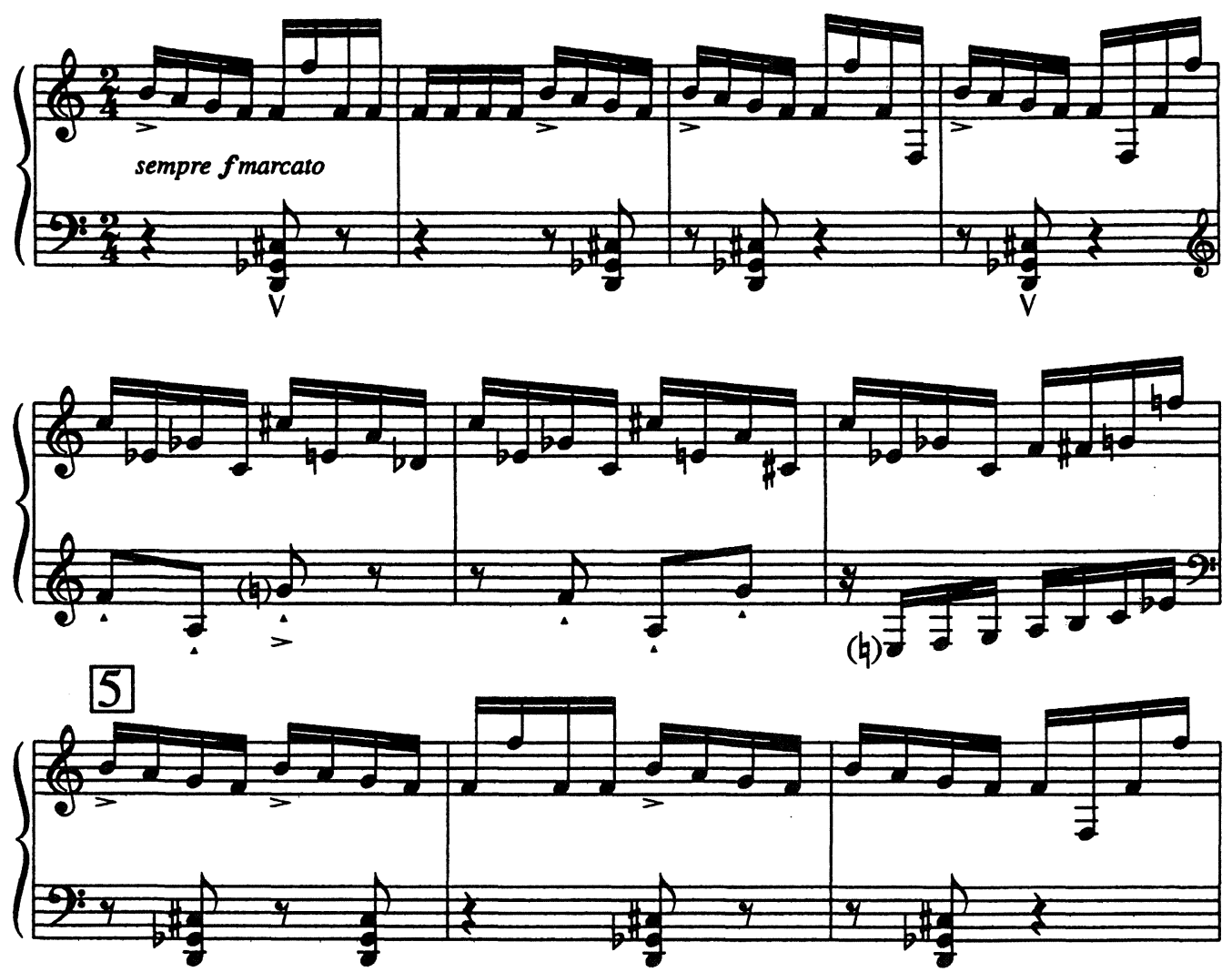

\section{A propósito de la disposición cíclica de Siete Canciones populares Españolas}

No existen en los documentos de la vida de Falla signos que hagan suponer una planificación cíclica de Siete Canciones populares Españolas. Los modelos populares pertenecen a colecciones dispares y tienen su origen en regiones diferentes de la geografía española. La mayor parte es de origen andaluz - El paño moruno, Canción, Nana y Polo_-, una canción es levantina, - Seguidilla murciana - otra aragonesa - Jota - por último una canción norteña - Asturiana-. No existe tampoco una perspectiva de narración común, a excepción de la primera canción, cantada en la tercera persona, canta un narrador en primera persona, que fluctúa entre el punto de vista femenino y el masculino. El hecho de que las canciones fueran escritas en un principio para una sola cantante nos lleva a pensar, que estas diferentes perspectivas de narración no son más que diferentes roles en los que un intérprete singular va introduciéndose sin por ello "cambiar de tercio". 
El hecho de que la tesitura de la voz en todo el ciclo abarque sólo una décima apoya la hipótesis de que la intención de Falla era componer no sólo un conjunto de canciones, sino una obra con intencionalidad cíclica, que pudiera ser interpretada sin problemas por un sólo intérprete. No se debería sobrevalorar esta circunstancia, ya los modelos melódicos populares y la intención de Falla de mantener el tono popular en sus adaptaciones tienen como consecuencia obligada, el no utilizar un ámbito demasiado ancho, y con ello demasiado belcantístico. No obstante existe un detalle, que sí podría ser considerado como indicio de una intencionalidad cíclica. Observemos las tonalidades originales de las adaptaciones:

1. El paño moruno:

2. Seguidilla murciana:

3. Asturiana:

4. Jota:

5. Nana:

6. Canción:

7. Polo: si menor

fa mayor

fa menor

mi mayor

mi menor

sol mayor

mi frigio

Es posible discernir un orden en la distribución de las tonalidades, que en ningún caso, se puede deber a las tonalidades del documento popular - e. g. la tonalidad de Mi mayor es extremadamente incómoda para voces laicas-. La alternancia de tonalidades mayores y menores con la misma tónica a partir de la segunda canción, la relación de segundas y terceras entre las diferentes tonalidades, y la relación de quinta - si-mi- entre las tonalidades de las canciones que enmarcan el ciclo (podemos interpretar aquí el mi frigio de la $7^{\text {a }}$ canción como alternativa a la tonalidad paralela menor de sol mayor), dan fe de una organización racional del material tonal con el fin de infundir a una serie de canciones, muy distintas en tono y en forma, unidad musical propia. Y precisamente éste es un elemento artificial, en el sentido, de que sólo dónde hay un artífice singular, con ideas estéticas abstractas, cuya intención es la de producir una obra de arte, es posible observar el fenómeno de que la estructura, como elemento artístico en sí, se convierte en medio de unificación artística.

Por último podemos observar otro medio de crear unidad artística en la dimensión temática de los textos. Hasta ahora sólo he analizado los textos en tanto en cuanto portadores de una función formal y estructurante. El significado del texto juega igualmente un papel importante, que no podemos dejar de lado. Tenemos que intentar introducirnos en el lenguaje metafórico e insinuativo de texto, que se encuentra oculto en las capas más profundas del subconsciente popular, buscar detrás de la fachada de metáforas regionales y concretas el contenido último.

Todos los textos tratan directa o indirectamente de tema amoroso. Esto no se debe a una coincidencia sino una decisión consciente del autor, puesto que las melodías del ciclo presentan en sus diversas documentaciones textos diferentes con tema no amorosos. Ya indicaba al principio de este artículo que conocemos, y que Falla conocía, versiones textuales diferentes al menos de Canción. En su colección de adaptaciones populares Cantares de Nochebuena aparece la melodía 
con texto navideño, en la colección de canciones populares de Inzegna tenemos dos estrofas, una con un absurdo texto cómico y por fin la segunda estrofa que conocemos en la adaptación de Falla en Siete Canciones:

CANTARES DE
NOCHEBUENA
Un pastor lleva un pavo
y otro un carnero
y otro lleva la bota
"del aire"
del vino añejo
"madre a la orilla"
del vino añejo
"niña."
$* * *$

\section{CANTO DE GRANADA}

Un usía de Granada murió de ahíto

que se cenó en tres noches "del aire"

un huevo frito "madre a la orilla"

un huevo frito "madre."

Dicen que no me quieres ya me has querido vayáse lo ganado "del aire" por lo perdido "madre a la orilla" por lo perdido "madre."

\section{SIETE CANCIONES CANCIÓN}

Por traidores tus ojos voy a enterrarlos no sabes lo que cuesta "del aire" niña el mirarlos "madre a la orilla" niña el mirarlos "madre."

Dicen que no me quieres ya me has querido vayáse lo ganado "del aire" por lo perdido "madre a la orilla" por lo perdido "madre."

Queda demostrado el interés del autor, de permanecer en un nivel temático homogéneo.

Me permito aquí una corta digresión en la que quizá pueda explicar la fascinación que sentía Falla por esta singular canción popular. Todas las estrofas tienen, independientemente de la temática, un cierto aire de "nonsense". Los versos intercalados "del aire" y "madre a la orilla" aparecen en todos las estrofas sin que parezcan tener ninguna relación temática con el contexto, en suma, no significan nada. El núcleo del texto es siempre una copla de seguidilla:

$\begin{array}{ll}\text { Por traidores tus ojos } & 7 \\ \text { voy a enterrarlos. } & 5 \\ \text { No sabes lo que cuesta } & 7 \\ \text { niña el mirarlos. } & 5\end{array}$

Una característica de la copla de seguidilla, con su alternancia de hepta y pentasílabos, es que normalmente se puede considerar cada par de versos como dodecasílabo con cesura irregular y tres acentos métricos regularmente distribuidos: dos acentos métricos recaen sobre el heptasílabo, el tercer acento sobre el pentasílabo. Este hecho queda reflejado en la melodía popular en 
la organización de la melodía en grupos de tres compases por cada par de versos. Los dos primeros versos con su repetición tiene la forma métrica $3+3$ compases. El segundo par de versos, en cambio, presenta los arriba indicados versitos intercalados. El poeta anónimo modificó con estos versos absurdos la estructura de la copla de seguidilla del siguiente modo:

$\begin{array}{lr}\text { No sabes lo que cuesta "del aire" } & 10 \\ \text { niña el mirarlos "madre a la orilla" } & 10 \\ \text { niña el mirarlos "madre" } & 7\end{array}$

La forma del texto de estos versos no es ya la de dodecasílabos con tres acentos métricos sino de decasílabos, respectivamente heptasílabo con dos acentos métricos, lo que en la melodía queda reflejado en la agrupación de compases por pares. La forma de toda la estrofa es por tanto:

$$
12=(3+3)+(2+2+2) \text { compases }
$$

Los versitos intercalados tiene, lo que es remarcable en obras populares, únicamente una función métrica y formal. En el autógrafo de los Cantares de Nochebuena vemos que Falla subrayó doblemente los versitos intercalados, lo que quizá es una prueba de su atención a la característica disposición métrica de la melodía ${ }^{31}$.

Falla eligió canciones y textos que iluminan el tema amoroso desde distintos puntos de vista y las ordenó de forma dramáticamente lógica. La primera canción, El paño moruno es una metáfora sobre la pérdida de la inocencia, de la virginidad. El "paño fino", la joven, ha perdido la inocencia y con ello su "valor". La segunda canción caracteriza a la amada o al amado. El narrador habla de alguien tornadizo y volandero. La tercera canción trata de la búsqueda de consuelo la siguiente tematiza el conocido topos de la visita a la reja de la amada y con ello la fortificación de la relación amorosa, Nana podría ser interpretada como "pars pro toto" de las consecuencias de tal relación. La penúltima canción relata la ruptura, el amado abandona a la mujer por sentirse traicionado. Por último oímos como la mujer o el hombre descargan su tristeza por la traición o por el abandono en un lamento, en el que se maldice el amor.

La temática, la disposición y el transcurso dramático nos recuerdan a Frauenliebe- und leben, Amor y vida de mujer, op. 42 de Robert Schumann, sobre textos de Adalbert von Chamisso. Chamisso relata aquí las diferentes etapas en la relación entre una mujer y un hombre desde la perspectiva de la mujer: primer visión, primer encuentro, declaración de amor, promesa de matrimonio, boda, primer hijo y muerte del esposo. El desarrollo dramático de los textos es, a diferencia de los textos de Falla, directo y explícito. No hay elipses ni paréntesis retardantes. Schumann reinterpretó el final añadiendo tras la última canción una reminiscencia musical al principio del ciclo lo que de paso, implica un visión esperanzadora. Falla abandona al protagonista en su desesperación y maldición del amor. La analogía es, no obstante, evidente. En los documentos de la vida de Falla no existen indicios claros de que Falla conociera el ciclo de Schumann y siempre es más fácil demostrar el conocimiento de obras que el desconocimiento, pero sabemos,

31. Véase ejemplo 1. 
por la biografía de Pahissa, que Falla estudió junto con Pedrell la obra liderística de Schubert y Schumann. Aún más, su canción de juventud Olas Gigantes de 1900 muestra claras reminiscencias a la segunda canción del ciclo de Schumann Er, der Herrlichste von Allen y al comienzo de la Fantasía op. 17 también de Schumann, obra que interpretó Falla en una gira de conciertos durante el tiempo de composición de Olas Gigantes. Falla conocía tanto la obra liderística como la obra pianística de Schumann con seguridad y sus obras de juventud dan fe de un conocimiento activo. Aun cuando nos falten las pruebas concretas, los indicios hablan por sí mismos.

Siete Canciones populares Españolas conjuga así dos tradiciones preexistentes en el repertorio liderístico romántico: por una parte la disposición cerrada y cíclica, no estamos aquí ante una colección de siete canciones, sino ante una unidad musical, textual y dramática orgánicamente construida; por otra parte la adaptación de música popular como ya lo hicieran en el pasado Beethoven, Brahms o Schubert ${ }^{32}$. Pero, así como es innegable el carácter epigonal de sus canciones de juventud con respecto al repertorio anterior, es igualmente innegable, si nos atenemos a las observaciones realizadas aquí por muy fragmentarias y puntuales que sean, que Siete Canciones no sólo están en la línea y tradición de estas canciones, sino que transcienden lo transmitido para crear algo nuevo, original y propio con valor artístico ejemplar.

Podría ahora reprochárseme que no he hecho en este artículo más que describir lo conocido. Creo, no obstante con Hegel, que "das Bekannte überhaupt ist darum, daß es bekannt ist, nicht erkannt" "33 "lo conocido no es, por el simple hecho de ser conocido, comprendido". Sólo si intentamos verbalizar nuestras intuiciones con respecto a lo admirado, podemos comprender porqué es digno de admiración.

32. Como ejemplos cito aquí las adaptaciones de canciones escocesas, irlandesas y galas Op. 108 y WoO 152-156 de Beethoven así como sus adaptaciones de canciones de diversas naciones WoO 157-158. En el caso de Brahms son quizá los Acht Zigeunerlieder, op. 103 y sus adaptaciones de canciones alemanas WoO 31-33, sus obras más representativas. En el caso de Schubert no tenemos más que pensar en su Heidenröslein.

33. Georg Wilhelm Friedrich Hegel: Phänomenologie des Geistes, Würzburg Bamberg 1807, p. XXXVI. 